\title{
Mitral valve hypoplasia in children with isolated coarctation of the aorta
}

\author{
Poothirikovil Venugopalan, Frances A Bu'Lock, Hyam S Joffe
}

\begin{abstract}
Objective-To test the hypothesis that isolated coarctation of the aorta is associated with relative hypoplasia of the mitral valve, even when the valve is morphologically normal.

Design-Cross sectional and Doppler echocardiography were used in a prospective, paired, case control study to compare mitral valve dimensions and diastolic transmitral flow characteristics as indices of left heart development. 40 children with isolated coarctation and $\mathbf{4 0}$ size matched controls were examined. Within the coarctation group 14 children with apical diastolic murmurs were compared with 14 size matched patients without murmurs.
\end{abstract}

Setting-A supraregional tertiary referral centre for paediatric cardiology.

Outcome measures-Mitral valve diameters, measured from the parasternal long axis, short axis, and apical four chamber views; mitral valve cross sectional area measured from the parasternal short axis view; peak early (E) and peak atrial (A) phase diastolic transmitral flow velocities measured by pulsed wave Doppler from the apical four chamber view; derived $E / A$ ratio and pressure half time of decay from peak $E$.

Results-Mitral valve dimensions were significantly smaller in children with coarctation than in controls for long axis diameter (median $1.74 v 1.90 \mathrm{~cm}, p=$ $0 \cdot 0001)$, short axis diameter $(2 \cdot 21 v 2 \cdot 28$ $\mathrm{cm}, \mathbf{p}=0.027$ ), and cross sectional area $\left(2.37 v 3.15 \mathrm{~cm}^{2}, p=0.001\right)$. Peak $E$ and $A$ velocities were significantly higher in patients than in controls $\left(0.9 v 0.82 \mathrm{~ms}^{-1}, \mathrm{p}\right.$ $=0.013$ and $\left.0.61 v 0.51 \mathrm{~ms}^{-1}, \mathrm{p}=0.007\right)$. The only difference between children with coarctation plus murmurs and those without murmurs was a marginally longer pressure half time.

Conclusions-Smaller mitral valve dimensions and increased diastolic transmitral flow velocities in children with isolated coarctation compared with normal children suggests that coarctation may be part of a generalised hypoplasia of left heart structures.

(Br Heart f 1994;71:358-362)

It is well recognised that patients with coarctation of the aorta have a high incidence of left heart obstructive lesions such as sub-aortic stenosis, mitral, and aortic valve stenosis. ${ }^{12}$ It has been suggested that the coarctation may be a consequence of decreased aortic flow during embryogenesis. ${ }^{3}$ An alternative explanation is that both the aortic and intracardiac obstructive lesions are part of an overall hypoplasia of left sided structures resulting from a more generalised cause. Children with coarctation of the aorta often have a readily audible apical diastolic murmur even when there is no other evidence of mitral stenosis. ${ }^{4}$ This echocardiographic study was performed to investigate whether morphologically normal mitral valves were substantially smaller in children with coarctation of the aorta than in size matched paired controls, with both valve dimensions and transmitral flow patterns as study criteria. We also assessed whether the presence of an apical diastolic murmur in patients with coarctation related to especially small mitral valve dimensions.

\section{Patients and methods}

STUDY GROUP

Forty children under cardiological supervision for isolated aortic coarctation without mitral valve anomalies, aged between 17 days and 15 years, underwent detailed echocardiographic examination. The coarctation had been treated surgically in 35 of these children, between one day and 10 years (mean 2.8 years) previously. In five children, aged between 17 days and 8 years, the examinations were performed before operation. Twelve children required coarctectomy within the first 3 months of life, at between 2 days and 3 months (mean 1.2 months) of age. The other 28 underwent surgery at between 5 months and 14.8 (mean 4.7 ) years of age. The body surface area was calculated from measured height and weight for each patient. Forty more children, aged between 4 days and 16 years, were paired for body surface area and underwent identical examinations to form a control group. They comprised 27 children recovering after admission to hospital with minor ailments, nine with innocent systolic cardiac murmurs (normal cardiac anatomy) and four with trivial cardiac abnormalities. Two had tiny muscular ventricular septal defects, one had mild pulmonary valve stenosis, and one had had previous surgical closure of a patent ductus arteriosus.

Fourteen of the children with coarctation had a mid-diastolic murmur detectable by auscultation. These children formed a 


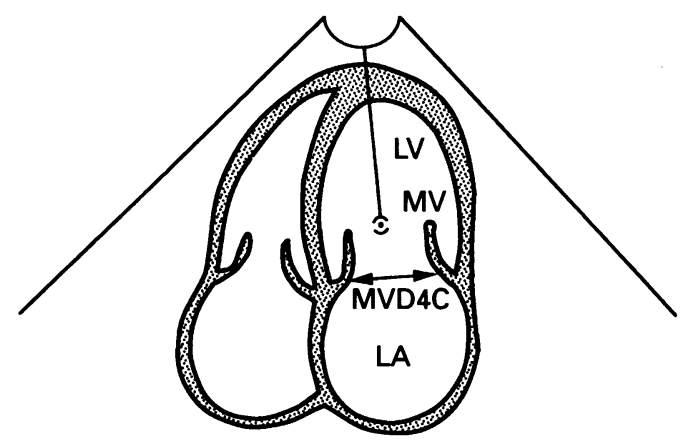

Figure 1 Apical four chamber view obtained by cross sectional echocardiography. The ultrasound transducer is positioned at the top of the image. The position of the pulsed wave Doppler sample volume between the tips of the mitral valve leaflets used to record transmitral flow velocity patterns is shown. MVD4C, mitral valve diameter measured from the apical four chamber view; $L V$, left ventricle; $L A$, left atrium; $M V$, mitral valve.

subgroup and were paired for comparison with the 14 children with most closely matched body surface areas and coarctation but without such murmurs.

\section{ECHOCARDIOGRAPHIC EXAMINATION}

All examinations were performed, recorded onto videotape, and analysed by one person with a Hewlett Packard 77020AC ultrasound scanner. Sedation was not used and the examination was performed in the left lateral semirecumbent position whenever possible. A full anatomical examination was performed to exclude other cardiac anomalies. Cross sectional images were recorded for quantitative analysis from the parasternal long axis, parasternal short axis, and apical four chamber views. The parasternal long axis view was standardised by ensuring that the aortic valve cusps were centrally situated within the aortic root, with minimal foreshortening of the left ventricle. In the parasternal short axis view, the transducer was first aligned to visualise the aortic root and was then angled inferiorly and leftward to accurately section the elliptical mitral valve ring. From the apical four chamber view showing least left ventricular foreshortening and maximal alignment with mitral inflow, both cross sectional images and pulsed wave Doppler spectral traces of transmitral inflow velocity patterns were recorded. The sample volume was positioned between the tips of the mitral valve leaflets (fig 1) and

Figure 2 Parasternal long axis view obtained by cross sectional

echocardiography. The ultrasound transducer is positioned at the top of the image. MVDLA, mitral valve diameter measured from the parasternal long

axis view;

aortic root; other

abbreviations as for fig 1 .

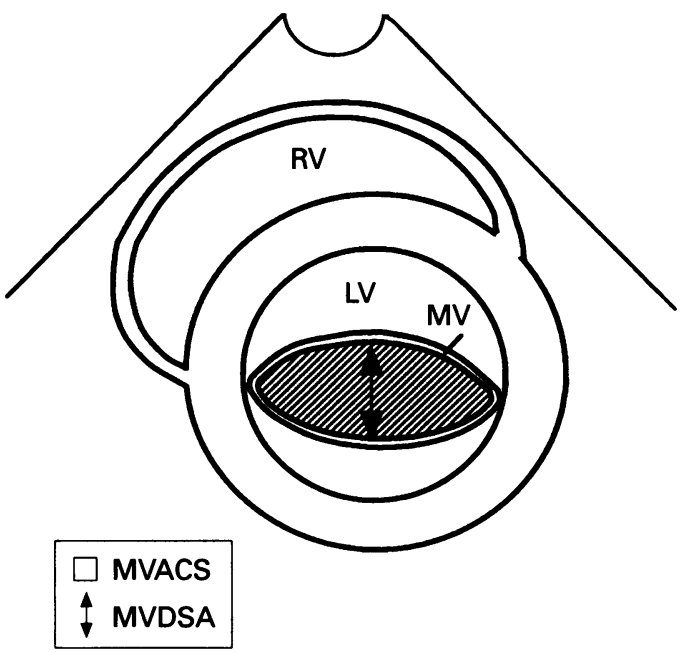

Figure 3 Parasternal short axis view obtained by cross sectional echocardiography. The ultrasound transducer is positioned at the top of the image. MVDSA, mitral valve diameter measured from the parasternal short axis view; MVACS mitral valve cross sectional area measured from the parasternal short axis view by planimetry; other abbreviations as for fig 1.

the position was adjusted at that level to acquire the highest quality traces possible.

\section{ECHOCARDIOGRAPHIC ANALYSIS}

Analysis was performed by one person from the videotaped recordings, with the Hewlett Packard on line analysis package. Mitral valve diameter was measured in $\mathrm{cm}$ from the parasternal long axis, parasternal short axis, and apical four chamber views. Long axis diameter was measured at maximal diastolic excursion from the junction of the anterior mitral leaflet with the posterior wall of the aortic root to a point where the left atrial wall, left ventricular wall, and the posterior mitral leaflet met (fig 2). Short axis diameter was measured at the maximal diastolic excursion of the mitral valve between the commissures at the annulus (fig 3). Mitral valve diameter was measured from the apical four chamber view between the points at which the valve cusps joined the annulus at maximal diastolic excursion (fig 1). The mitral valve cross sectional area was measured at maximal diastolic excursion, by planimetry from the parasternal short axis view (fig 3 ).

From the recorded Doppler traces, peak early $\left(E\left(\mathrm{~ms}^{-1}\right)\right.$ and peak atrial $\left(\mathrm{A}\left(\mathrm{ms}^{-1}\right)\right)$ phase filling velocities were measured and the EA ratio calculated as E/A. The pressure half time of decay from peak $\mathrm{E}$ velocity was calculated in $\mathrm{ms}$ from the formula;

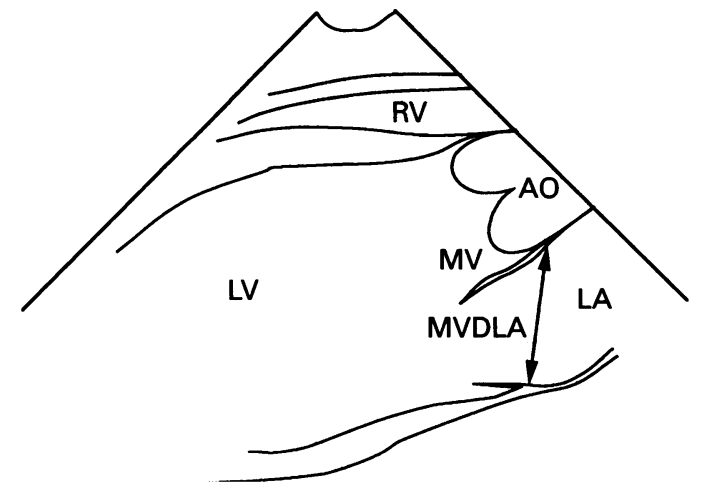

The results were analysed with the Statistical Package for the Social Sciences (SPSS-PC).

Both linear regression and correlation analy-
ses were performed, along with non-parametric

Both linear regression and correlation analy-
ses were performed, along with non-parametric

where $\mathrm{EDec}=$ the slope of the velocity decay from peak $\mathrm{E}$ in $\mathrm{ms}^{-2}$.

All measurements were taken as the mean of four cardiac cycles.

\section{STATISTICAL ANALYSIS}


Table 1 Patient data and echocardiographic variables

\begin{tabular}{|c|c|c|c|c|}
\hline & $\begin{array}{l}\text { Patients } \\
(n=40) \\
\text { median } \\
(I Q R)\end{array}$ & $\begin{array}{l}\text { Controls } \\
(n=40) \\
\text { median } \\
(I Q R)\end{array}$ & $\begin{array}{l}\text { Difference } \\
\text { from control } \\
\text { median } \\
(I Q R)\end{array}$ & $\begin{array}{l}\text { p Value } \\
\text { (Wilcoxon) }\end{array}$ \\
\hline $\operatorname{BSA}\left(m^{2}\right)$ & $\begin{array}{l}0.8 \\
(0.59 \text { to } 0.95)\end{array}$ & $\begin{array}{l}0.8 \\
(0.56 \text { to } 0.97)\end{array}$ & $\begin{array}{l}0 \\
(-2 \text { to } 1)\end{array}$ & $0 \cdot 28$ \\
\hline Age (yr) & $\begin{array}{l}6 \\
(2 \cdot 3 \text { to } 8)\end{array}$ & $\begin{array}{l}4 \\
(2 \text { to } 7)\end{array}$ & $\begin{array}{l}-0.13 \\
(-2 \text { to } 0)\end{array}$ & 0.007 \\
\hline MVDLA (cm) & $\begin{array}{l}1.74 \\
(1.4 \text { to } 1.9)\end{array}$ & $\begin{array}{l}1.9 \\
(1.6 \text { to } 2 \cdot 1)\end{array}$ & $\begin{array}{l}10^{\star} \\
(-2 \cdot 2 \text { to } 20)\end{array}$ & 0.0001 \\
\hline MVDSA (cm) & $\begin{array}{l}2.21 \\
(1.7 \text { to } 2 \cdot 5)\end{array}$ & $\begin{array}{l}2 \cdot 28 \\
(2 \cdot 0 \text { to } 2 \cdot 6)\end{array}$ & $\begin{array}{l}11^{\star} \\
(-10 \text { to } 8)\end{array}$ & 0.027 \\
\hline MVD4C (cm) & $\begin{array}{l}2.01 \\
(1 \cdot 8 \text { to } 2 \cdot 3)\end{array}$ & $\begin{array}{l}2 \cdot 19 \\
(1 \cdot 7 \text { to } 2 \cdot 5)\end{array}$ & $\begin{array}{l}6 \cdot 4^{\star} \\
(-6 \text { to } 15)\end{array}$ & 0.07 \\
\hline $\operatorname{MVACS}\left(\mathrm{cm}^{2}\right)$ & $\begin{array}{l}2.37 \\
(1.7 \text { to } 3.4)\end{array}$ & $\begin{array}{l}3 \cdot 15 \\
(2 \text { to } 4 \cdot 2)\end{array}$ & $\begin{array}{l}28^{\star} \\
(7 \text { to } 46)\end{array}$ & 0.001 \\
\hline$E\left(m^{-1}\right)$ & $\begin{array}{l}(0.9 \\
(0.8 \text { to } 1 \cdot 1)\end{array}$ & $\begin{array}{l}0.82 \\
(0.7 \text { to } 0.9)\end{array}$ & $\begin{array}{l}-0.04 \\
(-0.26 \text { to } 0.04)\end{array}$ & 0.013 \\
\hline$A\left(m^{-1}\right)$ & $\begin{array}{l}0.61 \\
(0.5 \text { to } 0.7)\end{array}$ & $\begin{array}{l}0.51 \\
(0.5 \text { to } 0.6)\end{array}$ & $\begin{array}{l}-0.08 \\
(-0.17 \text { to } 0.01)\end{array}$ & 0.007 \\
\hline $\mathrm{E}: \mathrm{A}$ & $\begin{array}{l}1.58 \\
(1.4 \text { to } 1 \cdot 8)\end{array}$ & $\begin{array}{l}1.56 \\
(1.4 \text { to } 1 \cdot 8)\end{array}$ & $\begin{array}{l}0.1 \\
(-0.28 \text { to } 0.29)\end{array}$ & $0 \cdot 76$ \\
\hline PHTE (ms) & $\begin{array}{l}36 \cdot 2 \\
(26 \cdot 1 \text { to } 43 \cdot 3)\end{array}$ & $\begin{array}{l}32 \cdot 7 \\
(27 \cdot 2 \text { to } 37 \cdot 9)\end{array}$ & $(-12$ to $6 \cdot 6)$ & $0 \cdot 14$ \\
\hline
\end{tabular}

$\star \%$ difference from control rather than absolute units. A, peak velocity of the atrial phase of left ventricular filling; BSA, body surface area; E, peak velocity of the early (passive) phase of left ventricular filling; EA, EA ratio; IQR, interquartile range; MVACS, mitral valve cross sectional area measured from the parasternal short axis view; MVD4C, mitral valve diameter measured rom the apical four chamber view; MVDLA, mitral valve diameter measured from the parasterview; PHTE, pressure half time of decay from peak $E$ velocity.

comparative tests. Differences with $\mathrm{p}<0.05$ were judged to be significant.

The study was approved by the Bristol and Weston District Ethics Committee. Fully informed consent was obtained for all examinations, from the parents, and also from the older children where appropriate.

\section{Results}

Table 1 shows the size, age and echocardiographic variables for patient and control groups compared by paired Wilcoxon's ranked sign tests. The matching of body surface area was accurate, but the controls were significantly younger for the same body surface area $(p=0.007)$, with median age (interquartile range) of $6(2.3$ to 8$)$ years in the patient group and 4 (2 to 7) years in the control group. Linear regression analysis (table 2) confirmed the expected strong positive correlation of mitral valve dimensions with body surface area for both patients and controls, with Pearson correlation coefficient $(R)>0 \cdot 7$ $(\mathrm{p}<0.0001)$. Transmitral Doppler flow velocities were not clearly linearly related to body surface area, although pressure half time of the $\mathrm{E}$ wave was, with $R>0.5(\mathrm{p}<0.001)$.

There were highly significant differences in mitral valve dimensions and transmitral
Doppler flow velocities between the coarctation group and controls (table 1, figs 4 and 5). The difference between each patient and their paired control was calculated for each variable. Regression analysis of this difference against body surface area showed that the differences increased with body surface area $(R$ $>0.35$, with $p<0.02$ ) in those variables most closely correlated with size. Thus differences in mitral valve dimensions are expressed in table 1 as a percentage of control, whereas those for the variables not related to body surface area are expressed as absolute differences. As might be expected mathematically, percentage difference in dimension between patients and controls was greatest for mitral valve area measured by planimetry. This difference was significant between mitral valve area and diameters measured from the short axis and apical four chamber views $(p<0.01)$ but was smaller for those measured from the long axis view. Measurement of mitral valve diameter was more sensitive to differences between patients and controls when measured from the parasternal views than from the apical four chamber view $(p=0.01$ for comparison of the percentage differences), but there were no significant differences between measurements from the parasternal long or short axes.

The size of the differences between patients and controls was compared between those patients requiring coarctectomy under or over 3 months of age. There were no significant differences detectable between the two groups in either absolute or difference in mitral valve dimensions.

Both peak $E$ and $A$ velocities were higher in the patients with coarctation than the controls $(p<0.02)$, but the differences were numerically small (median $0.04(\mathrm{E})$, and $0.08 \mathrm{~ms}^{-1}$ (A)) and the E:A ratio was very similar. Pressure half time of the $\mathrm{E}$ wave was longer in the coarctation group, but the difference was not significant.

The data from the 14 patients with coarctation and diastolic murmurs (including the differences from their paired controls) were compared with the data (and differences from paired controls) from the 14 patients with coarctation without murmurs whose body surface area most closely matched those with murmurs. Pressure half time for the $\mathrm{E}$ wave was longer in the patients with murmurs, median (interquartile range) 37.7 (32.8 to $44 \cdot 1) \mathrm{ms}$ as opposed to $29 \cdot 4(25 \cdot 3$ to 39$) \mathrm{ms}$ in those without. This difference just failed to

Table 2 Correlation of age and echocardiographic variables with body surface area

\begin{tabular}{|c|c|c|c|c|c|c|c|c|}
\hline & \multicolumn{4}{|c|}{ Patients } & \multicolumn{4}{|c|}{ Controls } \\
\hline & $R$ & Slope & $y$ Intercept & $p$ value & $R$ & Slope & $y$ Intercept & p Value \\
\hline $\begin{array}{l}\text { Age (yr) } \\
\text { MVDLA (cm) } \\
\text { MVDSA (cm) } \\
\text { MVD4C (cm) } \\
\text { MVACS (cm }) \\
\text { E }\left(\mathrm{ms}^{-1}\right) \\
\text { A }\left(\mathrm{ms}^{-1}\right) \\
\text { EA } \\
\text { PHTE (ms) }\end{array}$ & $\begin{array}{r}0.96 \\
0.74 \\
0.81 \\
0.82 \\
0.83 \\
-0.05 \\
-0.29 \\
0.41 \\
0.56\end{array}$ & $\begin{array}{l}11 \cdot 3 \\
0 \cdot 87 \\
1 \cdot 4 \\
1 \cdot 05 \\
2 \cdot 5 \\
-0.03 \\
-0 \cdot 17 \\
0 \cdot 35 \\
21\end{array}$ & $\begin{array}{l}-3.3 \\
0.94 \\
1.02 \\
1.17 \\
2.9 \\
0.97 \\
0.76 \\
1.31 \\
20\end{array}$ & $\begin{array}{l}<0.0001 \\
<0.0001 \\
<0.0001 \\
<0.0001 \\
<0.0001 \\
0.77 \\
0.11 \\
0.02 \\
0.0002\end{array}$ & $\begin{array}{c}0.97 \\
0.88 \\
0.93 \\
0.91 \\
0.93 \\
-0.2 \\
-0.29 \\
0.29 \\
0.5\end{array}$ & $\begin{array}{c}10 \cdot 4 \\
1 \cdot 35 \\
1 \cdot 57 \\
1 \cdot 49 \\
5 \cdot 3 \\
-0 \cdot 08 \\
-0 \cdot 09 \\
0 \cdot 24 \\
12 \cdot 8\end{array}$ & $\begin{array}{c}-3 \cdot 3 \\
0.8 \\
1 \cdot 03 \\
0.94 \\
-0 \cdot 8 \\
0 \cdot 87 \\
0 \cdot 6 \\
1 \cdot 4 \\
22 \cdot 5\end{array}$ & $\begin{array}{c}<0.0001 \\
<0.0001 \\
<0.0001 \\
<0.0001 \\
<0.0001 \\
0.12 \\
0.03 \\
0.05 \\
0.001\end{array}$ \\
\hline
\end{tabular}

Abbreviations as for table 1 . 
Figure 4 Comparison of mitral valve dimensions in patients with coarctation (Coarct) with those of their size matched paired controls. Wilcoxon's matched pairs ranked sign test was used for comparisons. MVD4C comparisons. MVD4C mitral valve diameter measured from the MVDLA, mitral valve diameter measured from the parasternal long axis view. parasternal long axis view diameter measured from the parasternal short axis view.

Figure 5 Comparison of transmitral peak early (E) and peak atrial $(A)$ phase diastolic flow velocities in patients with coarctation (Coarct) with those of their size matched paired controls. Wilcoxon's matched pairs ranked sign test was used for comparisons.
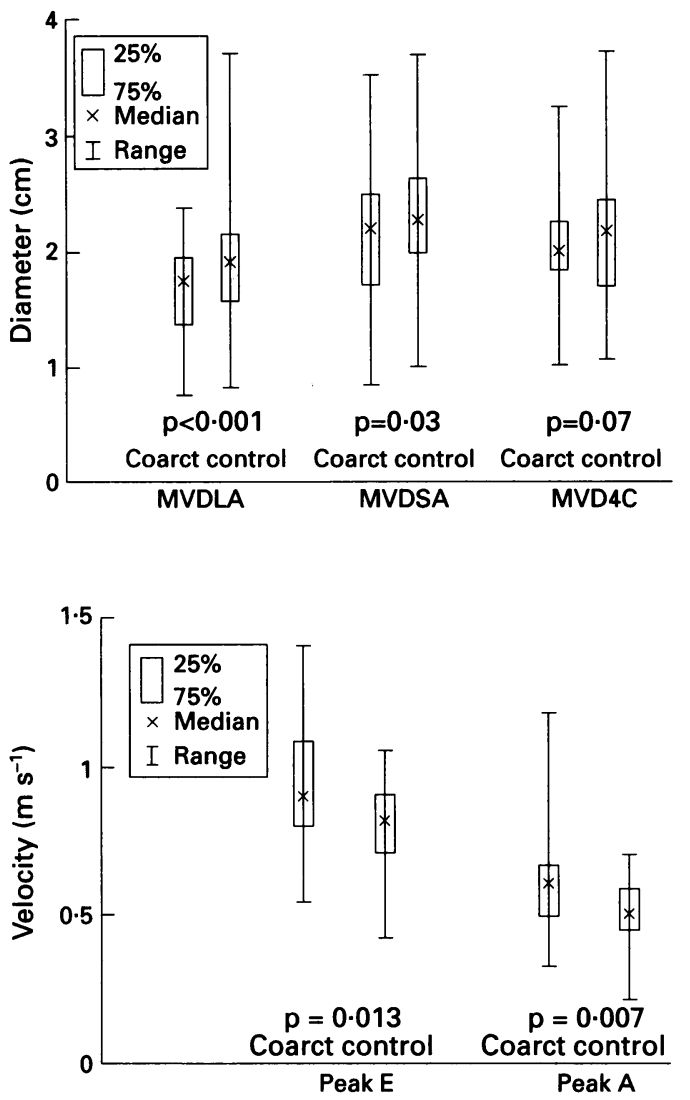

reach statistical significance $(p=0.07$ Wilcoxon). There were no other differences between these groups in either mitral valve dimensions or transmitral flow patterns, and neither group was different from its controls.

\section{Discussion}

A wide range of structural anomalies of the left heart have been reported in children with coarctation. In a cross sectional echocardiographic study of 56 patients with coarctation, Celano et al found major mitral valve anomalies in $12(21 \%)$ and minor anomalies in 21 (37\%). ${ }^{5}$ Between $16 \%$ and $23 \%$ of infants with coarctation have anatomically abnormal mitral valves detectable echocardiographically ${ }^{67}$ and abnormalities of the mitral or aortic valves were noted on review of 16 out of 19 young men who had been operated on in childhood for isolated aortic coarctation. ${ }^{8}$ Shone's syndrome ${ }^{9}$ (stenotic supravalvar mitral ring, parachute mitral valve, subaortic stenosis, and coarctation) is a serious combination of malformations, in which the severity of the mitral valve abnormality is the principal determinant of operative mortality. ${ }^{10}$ There are, however, few data on the sizes of leftsided structures in children with coarctation but otherwise normally formed hearts. Postmortem examination of 53 patients with an antemortem diagnosis of aortic coarctation found 34 with considerable mitral valve abnormalities ${ }^{1}$ but also 10 in whom the mitral valve was considered to be normally formed but small.
This case controlled echocardiographic study has examined the size of the normally formed mitral valves of 40 living children with isolated aortic coarctation, who might therefore be expected to be at the milder end of a spectrum of any associated left heart syndrome. Fourteen of these children had readily audible diastolic murmurs for which no anatomical cause was apparent.

The strong linear correlation of mitral valve dimensions with body surface area in the control group, supports the validity of such measurements from cross sectional echocardiographic images. Mitral valve dimension also correlated with body surface area in the patients with coarctation, but with a smaller $R$ (Pearson correlation coefficient) value. Closer examination of the data in table 2 shows that the $y$ intercept was similar or slightly higher in the patients with coarctation, but that the slope, or increase in dimension with body surface area, was less obvious. Thus the absolute differences between patients and controls changed with increasing body surface area, although the percentage difference was relatively constant. Although controls were younger than the patients with coarctation for the same body surface area, the overall relation between age and body surface area was similar.

Mitral valve diameters, measured from a number of differently orientated echocardiographic views, and mitral valve area measured by planimetry, were significantly smaller in children with coarctation than in paired size matched controls. The differences were most readily apparent from planimetry of the mitral valve area and from valve diameter measured from the parasternal long axis view. The considerable overlap of mitral valve dimensions between the groups and the relatively mild degree of mitral valve hypoplasia in these children, makes it unlikely that any diminution in foetal aortic flow would have been sufficient to result in coarctation on purely haemodynamic grounds. These results favour a more generalised pathogenesis and lend support to the hypothesis that these children are at the mildest end of a spectrum of left heart hypoplasia associated with coarctation of the aorta.

If this hypothesis is correct, it might be expected that children presenting early in life would be nearer the severe end of the coarctation spectrum and have relatively smaller mitral valves. Comparison of mitral valve dimensions in those requiring coarctectomy under and over 3 months in this study does not bear this out, but several confounding factors may be operating. The numbers overall are small, particularly for examination for subtle differences at the mild end of a spectrum of hypoplasia. The sizes of the two groups are very different, and real differences may be masked by variation in the interval between surgery and scanning, which was not controlled for in this small study. Further studies of left ventricular and aortic valve dimensions in patients with coarctation, are required to corroborate this hypothesis. 
Both peak early (E) and atrial (A) phase left ventricular filling velocities measured by Doppler echocardiography were significantly higher in the children with coarctation, although the E:A ratio was identical in the two groups. As there was no difference between the groups in pressure half time, a well accepted indicator of functional mitral stenosis in adults, the relative increase of peak $\mathrm{E}$ and $A$ velocities in the children with coarctation is of particular interest and might represent a more sensitive indicator of minor differences in effective mitral valve area. The noramal E:A ratio is probably consistent with the absence of any residual left ventricular outflow obstruction in most of the patients.

The only detectable difference between 14 pairs of coarctation patients with and without diastolic murmurs, matched for body surface area, was that the differences in pressure half time between patients and controls was greater in the presence of a murmur. This suggests a minor degree of relative functional mitral valve narrowing in those children with diastolic murmurs and adds further support to the idea of a spectrum of mitral valve hypoplasia in coarctation, those with murmurs perhaps being further from normal than those without. A much larger study, however, probably including children with associated mitral valve anomalies, would be required to confirm this.

In conclusion children with coarctation and otherwise anatomically normal hearts have smaller mitral valve dimensions than size matched controls. These differences are detectable by cross sectional echocardio- graphy and are associated with increased peak $\mathrm{E}$ and $\mathrm{A}$ transmitral flow velocities. It is likely that the relative hypoplasia of the mitral valve in children with isolated coarctation is greater in those who have audible diastolic murmurs. Children with isolated coarctation may represent the mildest end of an embryological spectrum of generalised hypoplasia of the left side of the heart, but further studies of left ventricular dimensions are required to support this hypothesis.

1 Rosenquist GC. Congenital mitral valve disease associated with coarctation of the aorta; a spectrum which includes parachute deformity of the mitral valve. Circulation 1974;49:985-93.

2 Becker AE, Becker MJ, Edwards JE. Anomalies associated with coarctation of the aorta. Particular reference to infancy. Circulation 1970;41:1067-75.

3 Rudolph AM, Heymann MA, Spitnas U. Hemodynamic considerations in the development of narrowing of the considerations in the development

4 Elizabeth WN, William HP, Jesse EE, Willis HW. Congenital heart disease. In: Hurst WJ, Schlant RCX, Rackley CE, Sonnenblick EH, Wenger NK, eds. The hackley CE, Sonnenblick EH, Wenger NK, eds.

5 Celano V, Pieroni DR, Morera JA, Roland JM, Gingell Celano V, Pieroni DR, Morera JA, Roland JM, Gingell
RL. Two-dimensional echocardiographic examination of mitral valve abnormalities associated with coarctation of the aorta. Circulation 1984;69:924-32.

6 Carminati M, Valsecchi O, Borghi A, et al. Aortic coarctation and associated abnormalities in the first year of life; echocardiographic diagnosis. G Ital Cardiol 1985;15: $400-6$. 7 First T, Skovranek J, Marek J, Tax P, Hucin B.
Echocardiographic diagnosis of aortic coarctation in neonates and infants. Cesk Pediatr 1990;45:265-8.

8 Wallentin I, Hanson E, Erikson BO. Non-invasive evaluation of the long-term results of coarctectomy in childhood. Clin Physiol 1988:8:121-8.

9 Shone JD, Sellers RD, Anderson RC, et al. The developmental complex of "parachute mitral valve", supravalvular ring of left atrium, subaortic stenosis and coarctation of the aorta. Am $₹$ Cardiol 1963;11:714-25.

10 Bolling SF, Iannettoni MD, Dick M, Rosenthal A, Bove EL. Shone's anomaly; operative results and late outcome. Ann Thorac Surg 1990;49:887-93. 